\title{
Construction of Innovative Thinking Teaching System for Professional Degree Postgraduates
}

\author{
Hairong Mi ${ }^{a}$, Chunli Wang ${ }^{b}$, Di Guan ${ }^{c}$, GuiFang Liu, Yong Sun \\ College of Aerospace and Civil Engineering, Harbin Engineering University, Harbin, 150001, \\ Heilongjiang, China \\ amihairong@hrbeu.edu.cn, bspring555555@126.com, cguandi@hrbeu.edu.cn
}

Keywords: professional degree postgraduates; innovative thinking; teaching system; teaching mode

\begin{abstract}
This paper, starting from the construction of the teaching system, discusses the course of training the graduate students of architectural and civil engineering. In the cultivation of creative thinking, we need to construct a complex curriculum target system of three main bodies, which are basic theory and knowledge, professional accomplishment and ability and scientific system thinking. The implementation of teaching mode will stimulate students' innovative potential and improve the quality of personnel training.
\end{abstract}

\section{Introduction}

The key to enhancing the capability of independent innovation and building an innovative country is talents, especially innovative talents. Graduate education is the main channel to cultivate innovative talents, and innovation ability occupies a very important position in all abilities of talents. Therefore, how to further improve the innovative consciousness and innovation ability of Postgraduates in the new situation is of great strategic significance[1].

There is a great difference between master's degree master and bachelor's degree master's degree. The master of bachelor's degree is mainly research frontier technology, and it belongs to scientific research type. However, professional master's focus is practical application ability, and it belongs to applied talent. Taking the graduate students of architectural and civil engineering as an example, the training goal of the graduate students in this field is a professional degree associated with the professional ability. The degree gainer should have the advantages of solid foundation, comprehensive quality and strong engineering practice ability, and becomes an applied and compound high level engineering technique with a certain creative ability. The talents of operation and engineering management have strong adaptability to the new equipment and tech moted the graduate students' creative practice ability, and achieved the results. nology in the future work, and have independent thinking ability and adaptability when facing the problems [2].

Our university has carried out a comprehensive reform in the training of the practical ability of the graduate student. It has actively explored the training mode, the curriculum system and the teaching methods, constructed the guarantee system of the graduate teaching quality.

\section{Training mode}

In order to develop the basic theory and practice ability of the graduate students of construction and civil engineering, our school implements the "double tutoring system" training model, which requires the students to practice the total time for no less than 1 years. The enterprise mentors are selected from the technical leaders of the state and provincial enterprises, and then the colleges and universities examine the qualifications of the tutors. The college tutors and enterprise tutors play the same role in the postgraduate training. College Tutors focus on the teaching of basic theory courses and basic research guidance for graduate students. Enterprise tutors focus on the practical application research and practical ability training of graduate students. College and enterprise tutors are responsible for the guidance and training of graduate students. This will enable students to 
integrate theory and practice well, and teachers can avoid focusing on theoretical phenomena due to lack of engineering experience [3]. From the perspective of teachers, they can complement each other and promote the improvement of mentor level. The joint training of graduate students with teachers and school tutors can allow school tutors and graduate students to integrate theory into engineering practice, and to test the school theory with problems in engineering practice. This joint training method can not only satisfy the needs of enterprise mentors to improve their theoretical level, but also meet the needs of school supervisors in strengthening theory with practice.

\section{Curriculum system}

According to the goal of adapting to the professional graduate degree curriculum system in architecture and civil engineering, the curriculum system should be optimized as shown in Fig.1.. It can build a composite curriculum target system based on the basic theory and knowledge, professional literacy and ability and scientific system thinking as shown in Fig.2.

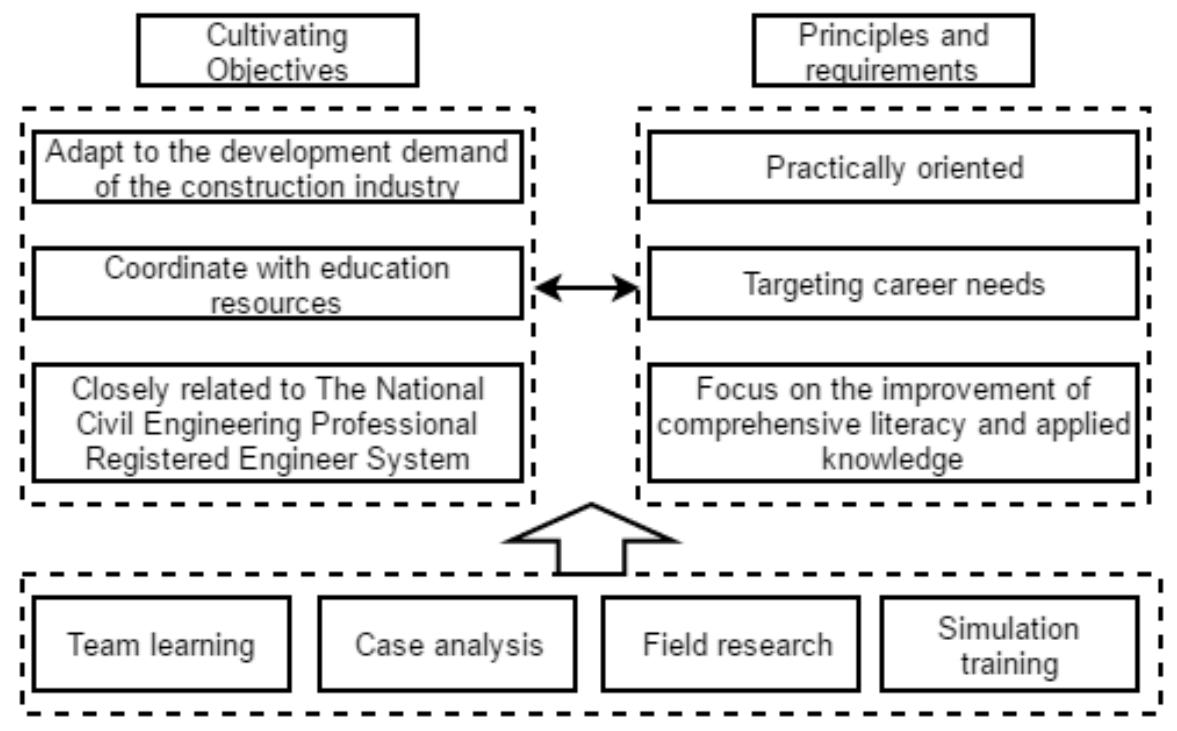

Fig.1 Optimization of Curriculum System

Basic theoretical knowledge is mainly divided into professional basic courses, comprehensive links and humanities courses. According to the direction of each student's research, professional basic courses choose different professional basic courses. The research directions are mainly divided into: structural earthquake resistance and reliability engineering, concrete materials and structures, Steel structures and composite structures, new materials and smart structures, heating ventilation and air conditioning engineering, municipal engineering and construction or finance and protection. Students can choose courses in other research directions according to their interests and specialties, which cultivate students' interdisciplinary perspective and systemic thinking[4]. The comprehensive links are divided into engineering practice courses and academic activities. The practical lessons include experiments, design, simulation, internships in and out of school, etc., to exercise students' practical ability and innovative spirit; academic activities include academic lectures, patent practice, and new technology and technology lectures in various fields. Through the lectures, students can understand new technologies in various fields and discuss problems encountered. They can also learn how to write patents for inventions. Humanities courses include English, philosophy, and moral education to improve students' humanistic qualities. 


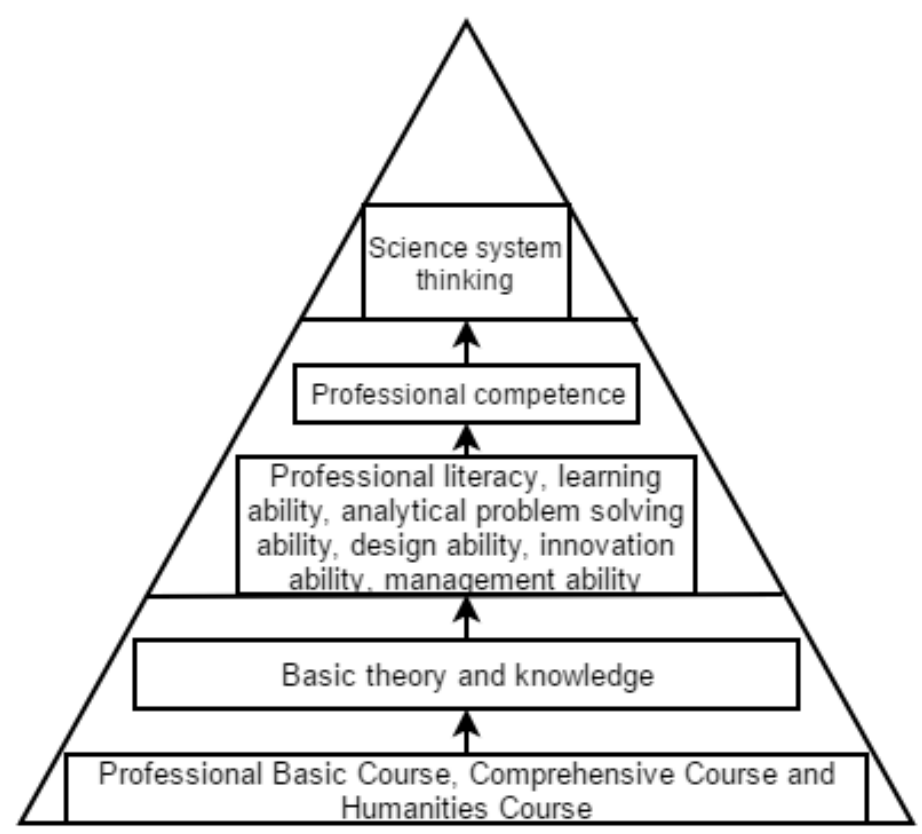

Fig.2 Composite course target system for degree graduates majoring

The improvement of professional accomplishment and ability is based on the basic theory and knowledge platform. Professional literacy requires students to have good engineering ethics, a strong sense of social responsibility, and rich humanistic qualities; learning ability requires students to have the ability to acquire information, update knowledge, and engage in life-long learning; analysis and problem-solving ability requires comprehensive application of architectural and civil engineering. The ability to theoretically and independently analyze and solve practical engineering problems; design capabilities require students to have the ability to explore new ideas and develop architectural product design and development, as well as the basic capabilities of building engineering project integration; innovation requires students to have follow-through innovation and integrated innovation. The technological innovation ability composed of original innovation; management ability requires good organization and management ability, strong communication, environmental adaptability and team cooperation ability[5].

The third platform is the thinking of the scientific system. It is gradually formed in the study of basic theory and knowledge and the cultivation of professional qualities and capabilities[6]. Systematic thinking requires students to think from a global perspective, develop divergent and convergent thinking, intuitive thinking and logical thinking, and have the ability to plan and foresee.

\section{Conclusion}

In summary, according to the characteristics of civil engineering disciplines, combined with business needs and the direction of the development of the discipline, it is clear that the orientation and objectives of professional degree training in architecture and civil engineering will improve the professional degree training links and improve the cultivation of training model and curriculum system. By comprehensively implementing the training mode of school-enterprise dual tutor system, we will continuously improve the training quality and the research ability and innovation ability of graduate students to solve practical technical problems.

\section{Acknowledgement}

In this paper, the research was sponsored by the Research Project on Teaching Reform of Harbin Engineering University (JG10217Y05); the Innovation Project of Seven Education in Harbin Engineering University ("Practice on the Values Education Mode of Introductory Course Teaching”); the Research Project on Teaching Reform of Harbin Engineering University 
(JG2016BYB06, JG10217Y07); the Innovation Project of Seven Education in Harbin Engineering University ("Research and Practice on Education Mode of Engineering Ethics Based on the Outstanding Engineers Training Plans" and "Research on Approaches and Countermeasures of Restoring the Academic Integrity for Postgraduate Students”).

\section{References}

[1] MA Shi-ai,CHEN Bo-wang,YI Jin.The Research of Promoting Innovative Practice Ability of Graduate under the "Double First-class"Background Construction - Taking Professional Degree Graduate in the Field of Architecture and Civil Engineering for Example[J].Education Teaching Forum.2018(8).

[2] HUANG Xinming, FANG Yaping, ZHAO Yang. Exploration and Study on Training Pattern of Full-time Professional Degree Postgraduate in Civil Engineering_—Take Building and Civil Engineering of Guangzhou University as an Example[J].Journal of Educational Institute of Jilin Province, 2016, 32(10):112-115

[3] YOU Zhi-guo, TAO Zhi-qiang, HAN Jian-qiang, ZHOU Yun-long, YANG Li-hua. Study on Pratice Teaching Mode of Professional Degree Postgraduates in Full-time Architecture and Civil Engineering:Talking North China University of Science and Technology as Example[J].Journal of North China University of Science and Technology(Social Science Edition), 2017, 17(2):112-116.

[4] XIE Jianhe, XIANG Chenyu, LI Lijuan, ZHU Jiang, LIU Yixin, LIU Feng. Analysis and reform proposals on training system for full-time professional master of architecture and civil engineering[J].Journal of Architectural Education in Institutions of Higher Learning,2017, 26(6):32-37

[5] XIE Yan,ZHU Jiang,LIANG Jingbo. Discussion on the cultivation of civil engineering excellent engineers with PBL teaching method relying on the IAR.Journal of Architectural Education in Institutions of Higher Learning[J].2016,25(01):51-54

[6] XIE Yan,ZHU Jiang,SUN Nan-ping,WU Yan-hai. Discussion on the Development of PBL Teaching Mode in Colleges of Engineering under the Cooperation of Industry - university research[J].Guangzhou Chemical Industry, 2015(18):146-148. 